\title{
Prevalence of Intestinal Cryptosporidiosis in Malaysian Children with Malignancies
}

\author{
Lubna Mohamed Elbeshti, Fawzia Shawesh, Altayeb Elazomi, Rukman Awang Hamat
}

\begin{abstract}
Cryptosporidiumparvum is an opportunistic parasitic agent that has a world-wide distribution. This parasite can be severe and very difficult to manage in immunocompromised patients especially in children with malignancies. However, data on immunocompromised children in Malaysia is very much lacking. A cross-sectional study was conducted over ten months in Institute of Pediatrics, Hospital Kuala Lumpur. A self-administered questionnaire was used and medical records were obtained. Stool samples were examined for the Cryptosporidium oocyst by using two different techniques i.e. modified Ziehl-Neelsen stain and Immunochromatographic (ICT) assays (RIDA-Quick Cryptosporidium R-Biopharm, Germany).One hundred and five stool samples were collected from children with different types of malignancies. All stool samples were negative for Cryptosporidiumoocysts by two different techniques. (33.3\%) from those patients had history of admission to other wards, $(29.5 \%)$ had history of animal contact, $(24.8 \%)$ had history of swimming in public swimming pool. In terms of precautionary measures practiced, $(\mathbf{8 0 . 9 \%})$ and $\mathbf{( 7 5 . 2 \% )}$ washed their hands before and after eating, or after going to the toilet respectively. In addition, preventive measures that were also observed: (16.2\%) had history of admission to day-care center, $(2.9 \%)$ had history of drinking tap water, and $(0.9 \%)$ had history of travel. This study documented a zero prevalence rate of cryptosporidiosis amongst children with malignancies despite higher prevalence rates being reported in other developing countries. Our results may suggest that the children with malignancies are at low risk of acquiring cryptosporidiosis because of good personal hygiene, good infection control and practices in the hospital, and improve water supply system.
\end{abstract}

Index Terms- Cryptosporidium,Cryptosporidiosis, immunocompromised,. Ziehl-Neelsen, opportunistic.

\section{INTRODUCTION}

Cryptosporidiosis, which is caused by an intracellular protozoa of the genus Cryptosporidium, is still considered as an emerging infectious disease and causing of a wide spectrum of clinical diseases in both immunocompetent and immunocompromised individuals worldwide. Historically, the first case of human cryptosporidiosis was reported in a young child who presented with self-limited enterocolitis in 1976 (Nimeet al., 1976). Heighten attention on the importance of the disease derived from several reported cases of severe infections with significant morbidity and mortality in AIDS epidemics in 1980's (Current, 1984; Casemoreet al.,

Lubna Mohamed Elbeshti, Department of parasitology, Faculty of Medicine, University of Zawia, Libya.

Fawzia Shawesh, Department of Medical Laboratories, Faculty of Medical Technology, University of Zawia, Libya

Altayeb Elazomi., Department of Medical Laboratories, Faculty of Medical Technology, University of Zawia, Libya

RukmanAwang Hamat, Department of Faculty of Medicine and Health Sciences ,University Putra Malaysia
1985), and later from a massive outbreak in Milwaukee, Wisconsin in 1993 where 403000 people were involved (MacKenzieet al., 1995). Now, epidemiological data on the prevalence of cryptosporidiosis and its transmission in HIV patients has been rapidly accumulating, and several risk factors have also been identified as an important transmission route for cryptosporidiosis.

The prevalence of cryptosporidiosis in HIV patients with diarrhea has been reported to range from 0 to $100 \%$ (Hunter $\&$ Nichols, 2002). The differences in the prevalence of cryptosporidiosis are believed to be due to differences in the study methodology, geographical location, type of study population, and sensitivity and specificity of laboratory methods or stage of the disease (Hunter \& Nichols, 2002).

Direct contact with water contaminated with faeces or droppings of infected humans or animals, or hand-to-mouth transfer of oocysts from contaminated food or surfaces have been implicated in transmitting the parasite (Sulaimanet al., 1998; Quiroz et al., 2000; Havelaaret al., 2000). Recently, the use of highly active antiretroviral therapy (HAART) in HIV/AIDS patients has been associated with complete eradication of Cryptosporidium in gastrointestinal tract by immune reconstitution. The underlying mechanism for this is thought to be directly related to the replenishment of $\mathrm{CD} 4^{+}$cells in AIDS patients, rather than due to anti-parasitic activities of these drugs (Carr et al., 1998; Miao et al., )). Despite the general consensus on the opinion regard _ $1 e$ devastating consequences of Cryptosporidium infection in patients with HIV/AIDS and the importance of preventing them from infection, it does not seem to be a shared understanding of the risks to other groups of immunocompromised patients, especially children with malignancy. In these patients, cryptosporidiosis can also be severe and even fatal (Hunter \& Nichols, 2002).

There are relatively few studies, which investigate on the prevalence of Cryptosporidium in children with cancer in developing countries. Moreover, the epidemiology and clinical characteristics of cryptosporidiosis in these children in those countries are still scarce and probably under-reported. For instance, the only available data from Malaysia was published in 1999, which reported only $2 \%$ of children with cancer had cryptosporidium oocysts (Menon et al., 1999). In India, the prevalence of cryptosporidiosis in children with malignancies was $0.3 \%$ and $1.3 \%$, respectively (Rudrapantnaet al., 1997; Sreedharan, et al., 1996).

Nonetheless, higher prevalence of cryptosporidiosis (22\%) was reported in Iran among the similar immunocompromised group (Berenjiet al., 2007).

Interestingly, Cryptosporidiumoocysts can be detected in asymptomatic children with cancer. This was reported in $22 \%$ of those children with different types of cancers in the United States (Pettoello-Mantovaniet al., 1995). In addition, the parasite was also detected in $6.4 \%$ of healthy children in that 
country. Thus, this can be a potential reservoir for disease transmission among the patients. Previously, nosocomially acquired cryptosporidiosis has been reported in hospital staff (Koch et al., 1985; Martino et al., 1988; Ravnet al., 1991; Casemoreet al., 1994 ), and spread from a patient to another patient has also been documented (Ungaret al., 1990; Ravnet al., 1991; Casemoreet al., 1994). However, this does not attract much attention from the researchers. Thus, considering the characteristics of this parasite such as its robustness towards chlorine and acid (Carpenter et al., 1999; Dillingham et al., 2002), and low infective dose that can probably be as low as 10 oocysts are required for inducing infection (Okhuysenet al., 1999), one could imagine how such high numbers of immunocompromised children in a close setting such as in hospitals would be affected during nosocomial outbreaks. This further complicated by the absence of effective treatment regimen for the disease in immunocompromised children with cancer. Henceforth, in this current study, the object is to determine the prevalence and contributing factors of cryptosporidiosis among children with different types of malignancies and to investigate factors that might contribute to this infection in a single centre hospital. Thus, preventive measures can promptly be applied to minimize the risk of infection and limit the spread of the disease within this group of children. The main aim of this study was to estimate the prevalence of Cryptosporidiumin children with different types of malignancies. Also to identify contributing factors involved in the acquisition of Cryptosporidiumoocysts among children with different types of malignancies.

\section{Study Design and Location}

\section{MATERIAL AND METHODS}

The study was designed for a cross sectional study in Oncology ward, Institute of Pediatric, Hospital Kuala Lumpur. As well as in Laboratory of Parasitology of Faculty of Medicine and Health Sciences, UPM and Laboratory of Parasitology, UKM. This study was conducted over 10month durations from November 2009 until August 2010. One hundred and five stool samples were collected from children ( 56 boys, 49 girls) between the ages of 3 months and 17 years (mean age: 2 years). The majority of those children were the Malays (75.2\%), followed by the Chinese $(11.4 \%)$, Indians (8.6\%) and others (4.8\%).Most of these children have different types of malignancies. The most common type of lympho-hematopoietic malignancieswas acute lymphoblastic leukemia $(38.1 \%)$, followed by acute myeloid leukemia $(8.6 \%)$, suspected leukemia $(8.6 \%)$, lymphoma $(7.6 \%)$, and chronic myeloid leukemia (1.9\%). Whereas, among non-lympho-hematopoietic malignancies, brain tumor represented $11.4 \%$ of cases, followed by retinoblastoma (5.7\%), hepatoblastoma (3.8\%), Wilm's tumor $(2.9 \%)$, pleuropulmonaryblastoma $(1.9 \%)$ and right adrenal cortical tumor $(0.9 \%)$. All other the information got from medical records. It was included type of malignancies, laboratory parameters, and treatment.

Fresh stool samples were collected from patients into wide mouth screw cap clean containers.

Stool samples were transported in a cool box to Laboratory of Parasitology, Faculty of Medicine and Heath sciences, UPM, and divided into two parts, first part for Immunochromatographic (ICT) assays, i.e. RIDA-Quick
Cryptosporidium (R-Biopharm, Germany). Second part frozen at $-20{ }^{\circ} \mathrm{C}$ and kept until transported to Laboratory of Parasitology, UKM for staining.

A self administered questionnaire was given to one parent or guardian after stool sample was taken from the patients. The questionnaires consist of four parts,

i. The first part consists of sociodemographic data of the patient such as age, gender, ethnicity, number of sibling. The age of the patients was categorized.

ii. The second part of questionnaire consists from five parts. This was about the information on the patient. This includes main complaint at admission, duration of admission (date of admission, date of discharge), history of underlining medical illness prior to admission, history of malignancy.

iii. The third part of questionnaires consists of eight parts. This was about the symptoms related to intestinal cryptosporidiosis. This includes fever, diarrhea, foul smelling stool, stool mixed with mucus, stool mixed with blood, vomiting, nausea, cramping abdominal pain.

iv. The fourth part of the questionnaire consists from eight parts. This was about the risk factors of intestinal cryptosporidiosis. Which includes source of drinking water, washing the hands before and after eating, washing the hands after using the toilet, history of swinging in swimming pools, history of animal contact, history of admission to day-care centers, history of admission to other wards and history of recent travel.

Immunochromatographic (ICT) assays RIDA- Quick Cryptosporidium (R-Biopharm, Germany) procedure

The procedure was done according to manufacturer's guideline. About 50mg of fresh stool sample was placed into a tube containing $1 \mathrm{ml}$ of extraction buffer then homogenized on a vortex mixer.

The sample was allowed to settle done for 3 minutes. A red test band along with the blue control band was positive. Whereas the blue control band appears negative.

\section{Statistical Methods}

Data analysis was performed by using Statistical Package for Social Sciences (SPSS) version 18. All important data were entered and have been calculated. Clinical parameters were obtained from medical records. We could not determine the association between the variables according to the negative results.

\section{III.RESULTS}

\section{Detection of Intestinal Parasites in Stool samples} Collected from Children with Malignancies

Of 110 stool samples collected, no Cryptosporidiumoocysts $(0 \%)$ were detected through modified Ziehl-Neelsen Stain and RIDA-Quick Cryptosporidium (R-Biopharm, Germany) in this study. Similarly, none of 97 samples $(0 \%)$ that were screened by routine stool examination for the ova and cyst were positive for helminthes and other protozoa. The negative result screened by RIDA-Quick Cryptosporidium (R-Biopharm, Germany) is shown in Figure 1. If the result is 
positive for Cryptosporidium, the red band will appear just below the blue band (control).

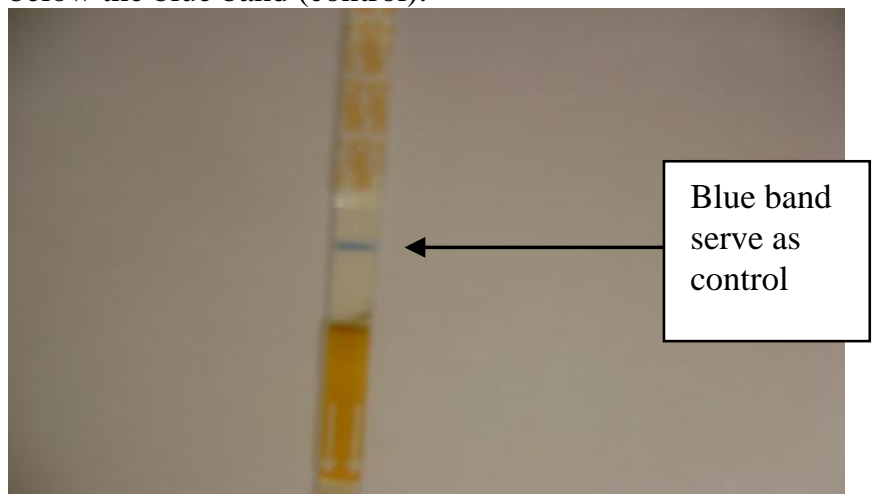

Figure 1: The negative Result of RIDA-Quick

\section{Cryptosporidium Stripe}

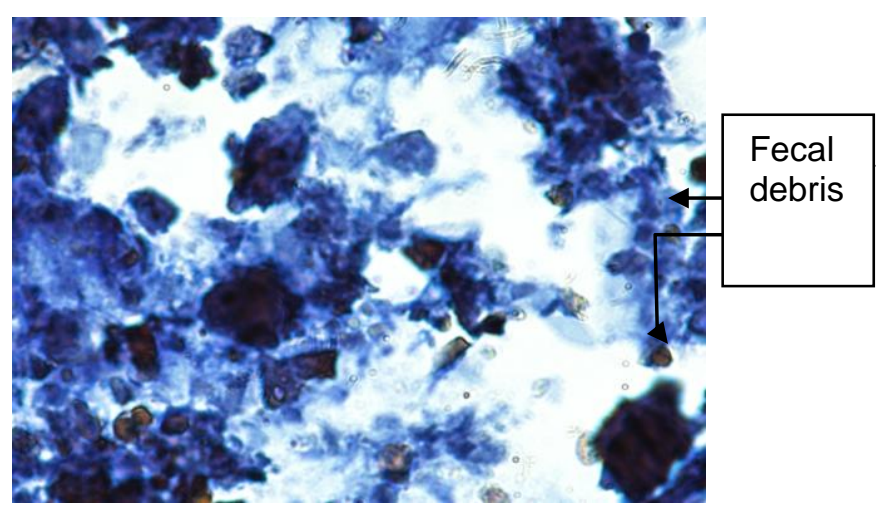

Figure 2: The negative Result of a fecal Smear Stained with modified Ziehl-

Neelsen stain (The photo was taking under magnification $100 \times$ )

\section{Socio-demographic Characteristics of Children with Malignancies}

Of 110 stool samples collected, 105 had a complete data on the socio-demographic characteristics (Table 4-1). The age of the respondents ranged from 3 months to 17 years old with the mean age of 2 and standard deviation of 0.88 years old. Among 105 children, [56 (53.3\%)] were males, whereas [49 (46.7\%)] were females. Malays represented the majority of the respondents, which were [79 $(75.2 \%)]$ followed by the Chinese [12 (11.4\%)], Indians [9 (8.6\%)] and others [5 $(4.8 \%)]$. The other ethnics were from KadazanDusun [3 $(2.9 \%)]$ and Bengali [2 (1.9\%)]. Meanwhile, sixty three $(60 \%)$ and $[42(40 \%)]$ of the respondents came from small and large families, respectively.
Table 1: Socio-demographic Characteristics among 105 Children with malignancies

Socio-demographic data $\quad \mathrm{n} \quad \%$

Age

$\begin{array}{lcc}\text { Less than 1 year } & 12 & 11.4 \\ \text { 1-6 years } & 60 & 57.1 \\ \text { 7-10 years } & 18 & 17.1 \\ \text { 11-14 years } & 14 & 13.3 \\ \text { More than } 14 \text { years } & 1 & 1\end{array}$

Gender

$\begin{array}{lll}\text { Male } & 56 & 53.3 \\ \text { Female } & 49 & 46.7\end{array}$

Ethnicity

$\begin{array}{lll}\text { Chinese } & 12 & 11.4\end{array}$

$\begin{array}{lll}\text { Indians } & 9 & 8.6\end{array}$

$\begin{array}{lll}\text { Others } & 5 & 4.8\end{array}$

Number of siblings

$1-3$

63

60

More than 3

42

40

Clinical Characteristics and Laboratory Parameters of Children with Malignancies

With regard to the clinical information obtained from the medical record (Table 4-2), most of the children admitted to oncology wards had fever [88 (83.8\%)]. This was followed by diarrhea [57 (54.3\%)], vomiting [47 $(44.8 \%)]$, nausea [43 $(41 \%)]$, offensive stool [39 (37.1\%)], mucus in stool [35 $(33.3 \%)$ ] and abdominal pain [20 (19\%)]. Only $4(3.8 \%)$ of them had blood in their stools. With reference to the type of diarrhea, $53(50.5 \%)$ and $4(3.8 \%)$ of them had acute and chronic diarrhea, respectively.

In addition, $64(71.1 \%)$ of the children had anemia with hemoglobin $(\mathrm{Hb})$ level below $11 \mathrm{~g} / \mathrm{dl}$, whereas $30(33.3 \%)$ of them had leucopenia with the total white cell count (WBC) below $5 \times 10^{9} / \mathrm{L}$. Forty two $(46.7 \%)$ of them had neutropenia with the number of neutrophils less than 1 to $\times 10^{9} / \mathrm{L}$. Meanwhile, $75(71.4 \%)$ of them underwent chemotherapy. Fifty two (49.5\%) and $48(45.7 \%)$ of them received antimicrobials and steroids, respectively 
Table 2: Description on Clinical Information of Children with Malignancies

\begin{tabular}{|c|c|c|}
\hline Clinical information & $\mathrm{n}$ & $\%$ \\
\hline \multicolumn{3}{|c|}{$\begin{array}{l}\text { Gastrointestinal manifestations } \\
(\mathrm{N}=105)\end{array}$} \\
\hline Fever & 88 & 83.8 \\
\hline Diarrhea & 57 & 54.3 \\
\hline Acute & 53 & 50.5 \\
\hline Chronic & 4 & 3.8 \\
\hline Vomiting & 47 & 44.8 \\
\hline Nausea & 43 & 41 \\
\hline Abdominal pain & 20 & 19.1 \\
\hline Offensive stool & 39 & 37.1 \\
\hline Mucus in stool & 35 & 33.3 \\
\hline Blood in stool & 4 & 3.8 \\
\hline \multicolumn{3}{|c|}{ Laboratory parameters $(\mathrm{N}=90)$} \\
\hline Anemia & 64 & 71.1 \\
\hline Leucopenia & 30 & 33.3 \\
\hline Neutropenia & 42 & 46.7 \\
\hline \multicolumn{3}{|l|}{ Others $(\mathrm{N}=105)$} \\
\hline Febrile neutropenia & 7 & 6.7 \\
\hline On chemotherapy & 75 & 71.4 \\
\hline On antimicrobials & 52 & 49.5 \\
\hline On steroids & 48 & 45.7 \\
\hline
\end{tabular}

Type of Malignancies Diagnosed in Children in Oncology Wards

Among 105 children, majority of them [68 (64.8\%)] were diagnosed with lympho-hematopoietic malignancies, whereas [37 (35.2\%)] of them were diagnosed with nonlympho-hematopoietic malignancies (Table 3). Acute lymphoblastic leukemia (ALL) was the most common lympho-hematopoietic malignancies diagnosed in these children, which constituted $40(38.1 \%)$ of them. The remaining types of malignancies comprised acute myeloid leukemia (AML) [9 (8.6\%)], lymphoma [8 (7.6\%)] and chronic myeloid leukemia (CML) [2 (1.9\%)]. However, 9
$(8.6 \%)$ of them were suspected to have leukemia. Among non-lympho-hematopoietic malignancies, brain tumor [12 $(11.4 \%)]$ was the most commonly diagnosed, followed by retinoblastoma [6 $(5.7 \%)]$, hepatoblastoma [4 $(3.8 \%)]$, Wilm's tumor [3 (2.9\%)], osteosarcoma [3 (2.9\%)], pleuropulmonaryblastoma [2 (1.9\%)] and right adrenal cortical tumor $[1(0.9 \%)]$. Six $(5.7 \%)$ of them had hematological disorders such as haemophagocycticlymphohistiocytosis [3 (2.9\%)], aplastic anemia [2 (1.9\%)] and pure red cell aplasia [1 (0.9\%)].

Table 3: Type of Cancers or Disorders in Children with Malignancies

\begin{tabular}{|c|c|c|}
\hline Type of cancers & $\mathrm{n}$ & $\%$ \\
\hline Lympho-hematopoietic malignancies & 68 & 64.8 \\
\hline Acute lymphoblastic leukemia & 40 & 38.1 \\
\hline Acute myeloid leukemia & 9 & 8.6 \\
\hline Chronic myeloid leukemia & 2 & 1.9 \\
\hline Suspected leukemia & 9 & 8.6 \\
\hline Lymphoma & 8 & 7.6 \\
\hline Non- lympho-hematopoietic malignancies & 37 & 35.2 \\
\hline Brain tumor & 12 & 11.4 \\
\hline Retinoblastoma & 6 & 5.7 \\
\hline Hepatoblastoma & 4 & 3.8 \\
\hline Wilm's tumor & 3 & 2.9 \\
\hline Osteosarcoma & 3 & 2.9 \\
\hline Pleuropulmonaryblastoma & 2 & 1.9 \\
\hline Right adrenal cortical tumor & 1 & 0.9 \\
\hline Hematological disorders & 6 & 5.7 \\
\hline Haemophagocycticlymphohistiocytosis & 3 & 2.9 \\
\hline Aplastic anemia & 2 & 1.9 \\
\hline Pure red cell aplasia & 1 & 0.9 \\
\hline
\end{tabular}

\section{Factors that Influence the Acquisition of Cryptosporidiosis in Children with Malignancies} Factors that might influence the acquisition of potential cryptosporidiosis were investigated as shown in Table 4. In general, [85 (80.9\%)] and [79 (75.2\%)] of our respondents washed their hands before eating and after using the toilet, respectively. Moreover, during our work at the oncology ward we noted the parents or the guardians of those children washed their hands before prepare of the milk formula or give 
the food to the children. Thirty-five (33.3\%) had history of previous admission to other wards, and [31 (29.5\%)] of them had history of contact with animals. Among children who had history of previous admission to other wards [20 (19\%)], [8 $(7.6 \%)],[4(3.8 \%)],[2(1.9 \%)],[1(0.9 \%)]$ had history of admission to the surgical wards, general ward, neurological ward, ophthalmology ward, intensive care unit respectively. Among children who had a history of animal contact, [17 $(16.2 \%)],[7(6.7)],[6(5.7 \%)]$ and [1 (0.9\%)] of them had a history of contact with cats, fish, dogs, and chicken, respectively. In addition, [26 (24.8\%)] had history of swimming, among those children [19 (18\%)], [4 (3\%)], [3 $(2.8 \%)]$ had history of swimming in swimming pools, river, sea respectively. Seventeen $(16.2 \%)$ had history of admission to day-care centres, [74 (70.4\%) [9 (8.5\%)] [5 (4.7\%)] they were looking after by their families, babysitters, grandmothers respectively. Surprisingly, only 3 (2.9\%) had history of drinking unfiltered tap water the rest of them used boiling water. Moreover, only one patient $(0.9 \%)$ had history of recent travel few weeks ago before admission to the hospital.

Table 4: Factors that Might influence the Acquisition of Cryptosporidiosis among 105 Children with Malignancies

\begin{tabular}{lcc}
\hline Factors & $\mathrm{n}$ & $\%$ \\
Washing hands before eating & 85 & 80.9 \\
Washing hands after using the toilet & 79 & 75.2 \\
History of previous admission & 35 & 33.3 \\
History of contact with animals & 31 & 29.5 \\
History of swimming & 26 & 24.8 \\
History of admission to day-care & 17 & 16.2 \\
centres & & \\
History of drinking unfiltered tap & 3 & 2.9 \\
water & & \\
History of recent travel & 1 & \\
\hline
\end{tabular}

\section{DISCUSSION}

Cryptosporidium has been recognized as a significant cause of gastrointestinal disease in both immunocompetent and immunocompromised people worldwide (Current \& Garcia, 1991; McColeet al., 2000). In healthy individuals, Cryptosporidium usually causes benign self limiting illness (Isaacs et al., 1985). Nonetheless, in severely immunocompromised people the disease can be chronic and life-threatening (Tzipori, 1987; Riggs et al., 1997; Langer \& Riggs, 1999; Amadiet al., 2002). However, studies on Cryptosporidium infection in humans are mainly focused on immunocompromised adult cases (HIV/AIDS patients) and only few studies have investigated the prevalence and risk factors related to cryptosporidiosis among immunodeficient children especially children with cancer. Moreover, data on the potential source of parasite in this group of children have not been well explored despite few cases of severe infection, which include death have been documented in some reports (Foot et al., 1990; Tumwineet al., 2003). In addition, most of the currently available data of cryptosporidiosis in oncology patients are also derived from studies in adult population. For instance, few studies reported that cryptosporidiosis developed as a result of immunosuppressive therapy used in cancer patients (Mead et al., 1986); while others documented the provocative effect of cryptosporidiosis towards aplastic crisis in these patients (Casemore, 1988; Foot et al., 1990). Moreover, clinical manifestations and significant morbidity were reported to be similar to that observed in HIV/AIDS patients (Gentile et al., 1991; Tanyukselet al., 1985; Sreedharanet al., 1996). Thus, in view of the devastating clinical consequences and the absence of effective drug for cryptosporidiosis, it is vital that more information is required about the disease in this group of children.

In the present study, all stool samples obtained from 105 children with or without diarrhea who were diagnosed with different types of malignancies did not reveal the presence of Cryptosporidiumoocysts. In our study, only one stool smear was used for mZN staining and the remaining specimen was subjected for coproantigen testing. This is not surprising as our finding is in accordance with a prospective study done by Burgneret al., (1999) in Australia. In their study, 149 stool samples from 60 children with malignancies who presented with diarrhea were stained ( 2 slides were prepared for each stool sample) with safranin-methylene blue technique and none were found to be positive for Cryptosporidiumoocysts. Khalil et al.,(1991) also found that stools of 111 children with different types of malignancies who underwent immunosuppressive therapy were also negative for Cryptosporidium. The stool was also subjected to a single stool examination technique. However, the type of staining method used could not be traced due to limited available information. In another study, Cryptosporidium was also not detected in 97 stool samples of 37 immunocompromised children (24 had acute leukemia and 7 had lymphoma). In their study, stool sample was submitted for more than one and several staining techniques were used such as carbolfuchsin rapid negative stain, modified Ziehl-Neelsen, Giemsa, methylene blue and acid fast stains (Kern et al., 1987).

On the contrary, different prevalence of cryptosporidiosis among children with cancer have been reported in a few studies and children less than 2 years of age are frequently infected in both community and hospital settings (Tziporiet al., 1983; Mata et al., 1984; Bern et al., 2002; Simango\&Mutikani, 2004; Priest et al., 2005). Recently, the highest prevalence was reported among 89 diarrheic children who were diagnosed with leukemia and lymphoma in Turkey (Tamer et al., 2008). In this study, they found that $12.4 \%$ and $7.9 \%$ of these children had cryptosporidiosis by using ELISA and Kinyoun's acid fast staining methods, respectively. In addition, $7(14.8 \%), 3(10 \%)$ and $1(8.3 \%)$ of children with ALL, CML and solid tumors, respectively were positive for Cryptosporidium by using one of these methods. EL-Mahallawyet al., (2004) reported 9.6\% of 104 diarrheic children with cancer had cryptosporidiosis in Egypt. In this prospective study, 10 of 104 stool samples were positive for 
Cryptosporidiumoocysts by using modified acid-fast stain and immunoperoxidase test with monoclonal antibodies.

Meanwhile, Tappehet al., (2011) reported that 3 of 72 (4.2\%) cancer children with or without diarrhea were found positive for Cryptosporidium in Pakistan. Among the positive ones, 2 and 1 of them were from rural and urban areas, respectively. In this case-control study, two samples were obtained from each child and were subjected to formol-ether concentration and modified acid fast staining techniques. Similar findings have been reported in two studies among children with cancer in Turkey and Iran. Aksoyet al., (2003) reported that 2 of 50 (4\%) symptomatic or asymptomatic children with different types of malignancies were found positive for Cryptosporidiumoocysts in their stool samples in Turkey. These children were diagnosed with leukemia (1) and lymphoma (1). In this study, modified formol-ether acetate concentration method was used and four smears were prepared for Trichrome (2 slides) and Kinyoun's acid-fast stains ( 2 slides). Meanwhile, a recent finding from a study conducted among 176 immunocompromised patients (children and adults) revealed that 2 of $48(4.2 \%)$ children with cancer had Cryptosporidium. In this study, one stool sample was used from each patient for the detection of Cryptosporidiumoocysts by ELISA technique.

In Malaysia, only one study has reported the prevalence of cryptosporidiosis in children with cancer (Menon et al., 1999). In this study, a total of 237 stool specimens were collected from 50 children with cancer ( 32 with leukemia and 18 with solid tumors) who were hospitalized for chemotherapy. Three consecutive stool samples were collected from each patient and stained with mZN. One of 10 samples collected from a child with retinoblastoma was positive for Cryptosporidium (2\%). In this case, there was no history of contact with animal although $50 \%$ of all subjects had history of animal contact. Based on these data, variations in the prevalence of cryptosporidiosis found in our study and others could be explained by the differences in socio-ecological factors, research methodologies and detection methods involved. Thus, it is very difficult to compare all the available data because of the absence of a universal "reference standard method" used in all studies (Hunter \& Nichols, 2002).

Nevertheless, the absence of Cryptosporidium in our study could be explained due to the number of sample obtained from our patient. We managed to get one single specimen from each child as the compliance of the parent was very poor. In addition, there was rapid turn-over of patients admitted in oncology wards and shorter duration of hospital stay. It has been known that children with cryptosporidiosis could intermittently release the Cryptosporidiumoocysts in their stools although the underlying mechanism for this is still unknown (Navinet al., 1984). Thus, we believe that the chance of detecting Cryptosporidium would have been higher if more than one stool specimen had been collected from each child. However, issues regarding the number of stool specimens that should ideally be submitted have been continuously debated for many decades. It is believed that the intensity of cryptosporidialoocyst shedding can vary over time in immunocompromised patients (Kuhls, 2000). However, there are few reports documented that 1 or 2 specimens can still be used in immunocompromised patients if acid-fast stain is employed as a diagnostic staining method
(Clavelet al., 1995; Blackman et al., 1997). In our study, mZN was used as a confirmatory staining technique. Many studies have used $\mathrm{mZN}$ stain as the gold standard for Cryptosporidium detection in clinical and research laboratories in many developing countries (Garcia et al., 1983;Arrowood\& Sterling, 1989; Brett et al., 2003; Caccio\&Pozio, 2006). In addition, the technique is relatively cheap, easy to perform without using special microscopes and able to simultaneously detect other pathogens such as Isospora and Cyclospora. This method is also able to differentiate green yeasts from red-stained oocysts (Kuhls, 2000). The sensitivity and specificity of this method are reported to be 40 to $90 \%$ and 50 to $85 \%$, respectively (Chakoet al., 2010).

The discovery of Cryptosporidium oocysts can be improved if the stool specimen is subjected to concentration techniques. In our study, all stool specimens were concentrated the formalin-ether method. Weberet al., (1992) reported that there was an increased of the recovery of oocysts by using formalin-ether concentration technique as compared to sucrose flotation and zinc sulfate flotation techniques. Waldman et al., (1986) proposed that ether sedimentation was better than sucrose flotation, as ether extracted lipids from the samples, thus dispersing the oocysts into the aqueous phase for easier recovery. Moreover, the sugar flotation technique is more cumbersome to perform, and the presence of the sugar solution of Sheather's (Sheather'set al., 1923) could inhibit staining procedures (Casemoreet al., 1985). Similarly, epidemiological data did not support the superiority of Sheather's sugar flotation for the detection of Cryptosporidium oocysts in stool specimens (McNabb et al., 1985).

Recently, the use of several copro-antigen tests or antigen detection assays have been employed as another diagnostic modality in detecting Cryptosporidium antigens in stool samples (Jexet al., 2008). In general, the specificity of these antigen detection assays such as EIA tests and dipstick kits is reported to be high (98-100\%) (Robert et al., 1990; Ungar, 1990; Newman et al., 1993; Garcia \& Shimizu, 1997; Chan etal., 2000; Kataniket al., 2001; Johnston et al., 2003), but the sensitivity of copro-antigen detection can be lower than most microscopic approaches (Johnston et al., 2003). Moreover, RIDA-Quick Cryptosporidium has more advantages than EIA tests as it is less time-consuming and simpler to perform, and do not require an ELISA microplate reader or other specialised equipment (Weitzelet al., 2006). For the diagnosis of Cryptosporidium infections, RIDA-Quick Cryptosporidium has been shown to perform better than EIA tests. The sensitivity and specificity of this method have been reported to be $98.8 \%$ and $100 \%$, respectively (Regnathet al., 2006). In our study, an immunochromatographic assay (RIDA-Quick Cryptosporidium, R-Biopharm, Germany) was used to detect the Cryptosporidiumantigens. Nevertheless, no Cryptosporidium oocysts were detected. This could be explained by the low number of antigens present in our stool samples, thus it might not be able to detect the Cryptosporidium antigens in our stool specimens. It has been known that low parasite densities might lead to false negative results (Ali \& Hill, 2003). In addition, the stool specimens that we processed might not be suitable for the detection of Cryptosporidiumantigens by using this test. Of 105, only [57 $(54.3 \%)]$ children had diarrhea with loose watery stools. The 
rest $(45.7 \%)$ had no diarrhea and probably had solid or semi-solid stools. A recent finding reported that by using native stool samples (semisolid or solid), the distribution of parasites might not be even that would also contribute to the failure of the detection (Current \& Garcia, 1991). This could also have contributed to the false-negative results obtained through the dipstick test in our study.However, it has been shown that the test might be useful if experienced practitioners of stool microscopy are not available, or for confirmation purposes. In addition, if only a single stool sample is available as observed in our study, the test can appropriately be used for the detection (Weitzelet al., 2006). Recent findings have suggested that this test can be used for the rapid and cost-effective screening of large numbers of stool samples (Garcia et al., 2003; Johnston et al., 2003). However, like other immunological methods, they do not allow the species or genotype of Cryptosporidium involved in the infection to be determined.

Another possible explanation that might contribute to the negative detection of Cryptosporidium is the immune status of the children in our study. Although patients with lympho-hematopoietic cancers are more prone to have devastating clinical outcomes compared to other type of cancers (Gentile et al., 1990; Travis et al., 1990; Tsaihonget al., 1990; Gentile et al., 1991), these unusual complications are believed to be directly related to the $\mathrm{CD} 4^{+}$lymphocyte count, and patients with $\mathrm{CD} 4^{+}$counts of less than 50 are at greatest risk for both severity of disease and prolonged carriage (Urban et al., 1996; Hoepelman, 1996; Theodos, 1998; Hunter \& Nichols, 2002; Udgiriet al., 2004; Abubakaret al., 2007).

In our study, we could not comment on the level of immune status of children with malignancies as the $\mathrm{CD} 4^{+}$count was not measured. Nevertheless, patients with leukemia or secondary to chemotherapy and steroids may have reduced phagocytic activity owing to neutropenic condition in their blood (Nelson et al., 1996). In addition, these patients might also have abnormalities in their cellular immune system (T-lymphocyte dysfunction) (Freifeldet al., 1997). In this condition, patients are relatively susceptible to opportunistic infections including cryptosporidiosis as the host defense mechanism is impaired. Studies in animal models (Heine et al., 1984) and in patients with AIDS (Soave et al., 1984; Pitliket al., 1983) have proposed that impaired T-lymphocyte function may lead to persistence cryptosporidiosis. Meanwhile, a recent study by Mahdi et al., (2007) reported that the immunoglobulin levels ( $\operatorname{IgM}, \operatorname{IgA}$ and $\operatorname{IgG}$ ) were also suppressed in patients with cancer and this might indicate the low antibody production by B-lymphocytes in response to particular antigen.

In general, based on these findings, it seems that the defect in the immune system of patients with hematologic malignancies is difficult to be characterized, as these cancers are associated with a broad spectrum of deficiencies involving both B and T cells. In our study, 33.3\% and 46.7\% of children had leucopenia and neutropenia, respectively, and only $6.7 \%$ of them had febrile neutropenia. In addition, $71.4 \%$ and $45.7 \%$ of them had received chemotherapy and steroids, respectively, as well. However, they seem to be at low risk of acquiring the disease. This might be related to the different degrees of immunosuppression in patients at the time of infection and during its course in our study or the immunodeficiency state might be transient and eventually returned to near normal immune function as proposed by Burgneret al (1999). Similar findings have been documented in a study conducted by Rudrapatnaet al., (1997). In this study, stools from 1,029 cancer patients who received or not received chemotherapy were all negative for Cryptosporidium.

Nevertheless, it seems that despite difference prevalences of cryptosporidiosis documented worldwide, studies on risk factors that might contribute to the acquisition of cryptosporidiosis among children with cancer are still lacking. This could also might influence directly or indirectly the number of infected children with cryptosporidiosis as well. In our study, most of these children hospitalized in oncology wards washed their hands before eating $(80.9 \%)$ and after using the toilet (75.2\%). In addition, only $16.2 \%$ and $33.3 \%$ had history of previous admission to day-care centres and other wards, respectively. Thus, the risk of exposure to Cryptosporidium in over-crowded places and hospital settings might be low in our study although information on risk factors among hospital personnel would also be necessary to be included as well, but this was beyond the scope of the current study. It is well known that cryptosporidiosis can be spread by person to person route of transmission as documented by the occurrence of day-care centres outbreaks (Alpert et al., 1986; Combee et al., 1986), multiple family infections (Soave \& Ma,1985), and sequential infections in hospitalized patients (patient to patient) and hospital staff (Koch et al., 1985; Ungaret al., 1990; Casemoreet al., 1994).

In addition, asymptomatic carrier among our patients was not detected. Thus, the potential risk of nosocomial outbreak is very low in our study. It is believed that asymptomatic carriage among children is quite common and can be a potential reservoir for cryptosporidiosis (Zaret al., 1985; Hunter et al., 2004). Meanwhile, other potential sources of cryptosporidiosis can also play important roles for the disease transmission. Drinking contaminated water of various sources, contact with domestic animals or pets, swimming in contaminated water and travelling have been identified as important risk factors among immuno-compromised patients (Seaton, 1992; Glaser et al., 1998; Pieniazeket al., 1999; Morgan et al., 2000a; Emmerson, 2001; Puechet al., 2001; Merlani\&Francioli, 2003; Kavanagh et al., 2005). In our study, only $0.9 \%, 2.9 \%, 24.8 \%$ and $29.5 \%$ had history of recent travelling, drinking unfiltered tap water, swimming and animals contact, respectively. Thus, this further minimized the risk of exposure to Cryptosporidium that might probably reflected by the absence of detection of this parasite. Recently, CDC has recommended measures to control and prevent this infection among people in the community as well as immuno-compromised individuals. This includes extensive hand washing, avoiding direct

\section{ACKNOWLEDGMENTS}

All authors contributed equally to the manuscript.

\section{REFERENCES}

[1] Abaza, S. M., Makhlouf, L. M., \& El-Shewy, K. A. (1995). Intestinal opportunistic parasites among different groups of immunocompromised hosts. J Egypt SocParasitol, 25(3), 713-727. 
[2] Abrahamsen, M. S., Templeton, T. J., Enomoto, S., Abrahante, J. E., Zhu, G., Lancto, C. A., et al. (2004). Complete genome sequence of the apicomplexan, Cryptosporidium parvum. Science 304, 441-445.

[3] Abubakar, I., Aliyu, S. H., Arumugam, C., Usman, N. K., \& Hunter, P. R. (2007). Treatment of cryptosporidiosis in immunocompromised individuals: systematic review and meta-analysis. Br J ClinPharmacol $63,387-393$.

[4] Agnew, D. G., Lima, A. A., Newman, R. D., Wuhib, T., Moore, R. D., Guerrant, R. L., et al. (1998). Cryptosporidiosis in northeastern Brazilian children: association with increased diarrhea morbidity. $J$ Infect Dis, 177(3), 754-760.

[5] Akira, S. (2001). Toll-like receptors and innate immunity. AdvImmunol, 78, 1-56.

[6] Aksoy, U., Erbay, A., \&Akisu, C. (2003). Intestinal parasites in children with neoplasma. Turkish J Pediatr, 45(2), 129-132.

[7] Akyon, Y., Erguven, S., Arýkan, S., Yurdakok, K., \&Gunalp., A. (1999). Cryptosporidium parvum in a group of Turkish children. Turk J Pediatr, 41, 89-96.

[8] Ali, S. A., \& Hill, D. R. (2003). Giardiaintestinalis. CurrOpin Infect Dis, 16, 453-460.

[9] Alpert, G., Bell, L. M., Kirkpatrick, C. E., Budnick, L. D., Campos, J. M., Friedman, H. M., et al. (1984). Cryptosporidiosis in a day-care center. $N$ Engl J Med., 311, 860-861.

[10] Alpert, G., Bell, L. M., \& Kirkpatrick, C. E. (1986). Outbreak of cryptosporidiosis in a day-care center. Pediatrics $77,152-157$.

[11] Amadi, B., Mwiya, M., Musuku, J., Watuka, A., Sianongo, S., Ayoub, A., et al. (2002). Effect of nitazoxanide on morbidity and mortality in Zambian children with Lancet, 360, 1375-1380.

[12] Anderson, B. C. (1983). Cryptosporidiosis. Lab. Med, 14, 55-56.

[13] Anon (2004). Preventing person-to-person spread following gastrointestinal infections: guidelines for public health physicians and environmental health officers. Prepared by a Working Group of the former PHLS Advisory Committee on gastrointestinal infections. Communicable Disease and Public Health 7, 362-384.

[14] Areeshi, M., Dove, W., yes Papaventsis, D., yes Gatei, W., Combe, P., Grosjean, P., et al. (2008). Cryptosporidium species causing acute diarrhea in children in Antananarivo, Madagascar. Annals of Trop Medicine and Parasitology, 102(4), 309-315.

[15] Arrowood, M. J. (1997). Diagnosis. CRC Press, Boca Raton, FL.

[16] Arrowood, M. J., Mead, J. R., Mahrtand, J. L., \& Sterling, C. R. (1989) Effects of immune colostrum and orally administered antis-porozoite monoclonal antibodies on the outcome of $C$. parvum infections in neona-tal mice. Infection and Immunity, 57, 2283-2288.

[17] Arrowood, M. J., \& Sterling, C. R. (1989). Comparison of conventional staining methods and monoclonal antibody-based methods for Cryptosporidiumoocyst detection. J ClinMicrobiol 27, 1490-1495.

[18] Barta, J. R., \& Thompson, R. C. A. (2006). What is Cryptosporidium? Reappraising its biology and phylogenetic affinities. Trends Parasitol 22, 463-468.

[19] Baxby, D., \&Hart., C. A. (1986). The incidence of cryptosporidiosis: a two year prospective survey in children's hospital. J Hygiene, 96, $107-111$.

[20] Benhamou, Y., Kapel, N., Hoang, C., Matta, H., Meillet, D., Magne, D., et al. (1995). Inefficacy of intestinal secretory immune response to Cryptosporidium in acquired immunodeficiency syndrome. Gastroenterology, 108, 627-635.

[21] Berenji, F., None, Z., Hamidreza, K., Zahra, B., Abdollah, B., \&Simin, H. (2007). Cryptosporidium Infection in Pediatric Patients with lymphohematopoitic malignancies. Iran J Ped 3, 247-251.
[22] Bern, C., Hernandez, B., Lopez, M. B., Arrowood, M. J., DeMerida, A. M., \& Klein, R. E. (2000). The contrasting epidemiology of Cyclospora and Cryptosporidium among outpatients in Guatemala. Am J Tropical Med Hyg, 63, 231-235.

[23] Bern, C., Ortega, Y., Checkley, W., Roberts, J. M., Lescano, A. G., Cabrera, L., et al. (2002). Epidemiologic differences between cyclosporiasis and cryptosporidiosis in Peruvian children. Emerg Infect Dis, 8, 581-585.

[24] Besser-Wick, J. W., Forfang, J., Hedberg, C. W., Korlat, H. J., Osterholm, M. T., \& Sterling, C. R. (1996). Foodborne outbreak of diarrhoeal disease associated with Cryptosporidium parvumMinnesota. Morbid Mortal Wkly Rep, 45, 783.

[25] Bhattacharya, M. K., Teka, T., Faruque, A. S. G., \& Fuchs, G. J. (1997). Cryptosporidium infection in children in urban Bangladesh. $J$ Trop Paed, 43, 282-286.

[26] Bialek, R., Binder, N., Dietz, K., Joachim, A., Knobloch, J., \&Zelck, U E. (2002). Comparison of fluorescence, antigen and PCR assays to detect Cryptosporidiumparvum in fecal specimens. DiagnMicrobiol Infect Dis, 43, 283-288.

[27] Bird, R. G., \& Smith, M. D. (1980). Cryptosporidiosis enteritis in man: parasite life cycle and fine structural pathology. J Pathol 132, 217-233.

[28] Blackburn, B. G., Mazurek, J. M., \&Hlavsa, M. (2006). Cryptosporidiosis associated with ozonated apple cider. Emerg Infect Dis 12, 684-686.

[29] Blackman, E., Binder, S., \&Gaultier, C. (1997). Cryptosporidiosis in HIV-infected patients: Diagnostic sensitivity of stool examination, based on number of specimens submitted. Am J Gastroenterol, 92, 451-453.

[30] Brandonisio, O., Marangi, A., Panaro, M. A., Marzio, R., Natalicchio, M. I., \&Zizzadoro, P. (1996). Prevalence of Cryptosporidium in children with enteritis in southern Italy. Eur J Epidemiol 12, 187-190.

[31] Brett, A. L., Melanie, M., \&Honorine, D. (2003). Ward Cryptosporidium Species: New Insights and Old Challenges. ClinInf Dis, 36, 903-908.

[32] Brondson, M. (1984). Rapid dimethyl sulfoxide-modified acid-fast stain of Cryptosporidiumoocyst in stool specimens. J ClinMicrobiol, $19,952-953$

[33] Burgner, D., Pikos, N., Eagles, G., McCarty, A., \& Steven, M. (1999). Epidemiology of Cryptosporidium parvum in symptomatic pediatric oncology patients. J Pediatr Child Health, 35, 300-302.

[34] Caccio, S. M., \&Pozio, E. (2006). Advances in the epidemiology, diagnosis and treatment of cryptosporidiosis. Expert Rev Anti Infect Ther, 4, 429-443.

[35] Carey, C. M., Lee, H., \& Trevor, J. T. (2004). Biology, persistence and detection of Cryptosporidium parvum and Cryptosporidium hominisoocyst. Water Research 38, 818-862.

[36] Carpenter, C., Fayer, R., Trout, J., \& Beach, M. J. (1999). Chlorine disinfection of recreational water for Cryptosporidium parvum. Emerg Infect Dis, 5, 579-584.

[37] Carr, A., Marriott, D., Field, A., Vasak, E., \& Cooper, D. A. (1998) Treatment of HIV-1-associated microsporidiosis and cryptosporidiosis with combination antiretroviral therapy. Lancet 351, 256-261.

[38] Carreno, R. A., Matrin, D. S., \&Barta, J. R. (1999). Cryptosporidium is more closely related to the gregarines than to coccidia as shown by phylogenetic analysis of apicomplexan parasites inferred using small-subunit ribosomal RNA gene sequences. Parasitol Res, 85, 899-904.

[39] Casemore, D. P., Armstrong, M., \& Jackson, B. (1984). Screening for Cryptosporidium in stools. Lancet i, 734-735.

[40] Casemore, D. P., Armstrong, M., \& Sands, R. L. (1985). Laboratory diagnosis of cryptosporidiosis. J ClinPatho, 38, 1337-1341. 
[41] Casemore, D., Sands, R., \& Curry, A. (1985). Cryptosporidium species a "new" human pathogen. J ClinPathol 38, 1321-1336.

[42] Casemore, D. P. (1988). Human cryptosporidiosis (3 ed). Edinburgh, Scotland: Churchill Livingstone.

[43] Casemore, D., Gardner, C., \&O'Mahony, C. (1994). Cryptosporidial infection, with special reference to nosocomial transmission of Cryptosporidium parvum: a review. Folia Parasitol. (Praha) 41, 17-21.

[44] CDC/EPA, 1999. Guidance for people with severely weakened immune system

[45] available from : <http://www.gov/safewater >.

[46] CDC Fact Sheet. Preventing cryptosporidiosis: A guide for people a. with compromised immune system

b. http://www.cdc.gov/ncidod/dpd/parasites/cryptosporidiosis/factsht_crypt o_prevent_ci.htm (accessed Jan. 28, 2011)

[47] Cevallos, A., Bhat, N., Verdon, R., Hamer, D., Stein, B., Tzipori, S., et al. (2000). Mediation of Cryptosporidium parvum infection in vitro by mucin-like glycoproteins defined by a neutralizing monoclonal antibody Infect Immun, 68(9), 5167-5175.

[48] Chako, C. Z. J., Tyler, W., Schultz, L. G., Chiguma, L., \&Beerntsen, B. T. (2010). Cryptosporidiosis in People: It's Not Just About the Cows. J Vet Intern Med 24, 37-43.

[49] Chalmers, R. M., Ferguson, C., \&Caccio, S. (2005b). Direct comparison of selected methods for genetic categorisation of Cryptosporidium parvum and Cryptosporidium hominis species. Int $\mathrm{J}$ Parasitol 35, 397-410.

[50] Chan, A. W., MacFarlane, I. A., \& Rhodes, J. M. (1989). Cryptosporidiosis as a cause of chronic diarrhoea in a patient with insulin-dependent diabetes mellitus. J Infect, 19, 293.

[51] Chan, R., Chen, J., York, M. K., Setijono, N., Kaplan, R. L., Graham, F., et al. (2000). Evaluation of a combination rapid immunoassay for detection of Giardia and Cryptosporidium antigens. J ClinMicrobiol 38, 393-394.

[52] Chapman, P. A., Rush, B. A., \&McLauchlin, J. (1990). An enzyme immunoassay for detecting Cryptosporidium in faecal and environmental samples. J Med Microbiol, 32, 233-237.

[53] Checkley, W., Epstein, L. D., Gilman, R. H., Black, R. E., Cabrera, L., \& Sterling, C. R. (1998). Effects of Cryptosporidium parvum infection in Peruvian children: growth faltering and subsequent catch-up growth. Am J Epidemiol 148, 497-506.

[54] Checkley, W., Gilman, R. H., Epstein, L. D., Suarez, M., \& Diaz, J. F. (1997). Asymptomatic and symptomatic cryptosporidiosis: their acute effect on weight gain in Peruvian children. Am J Epidemiol, 145, 156-163.

[55] Chen, W., Harp, J. A., \&Harmsen, A. G. (1993). Requirements for $\mathrm{CD}^{+}$cells and gamma interferon in resolution of established Cryptosporidium parvum infection in mice. Infect Immun, 61, 3928-3932

[56] Clavel, A., Arnal, A. C., \& Sanchez, E. C. (1995). Evaluation of the optimal number of faecal specimens in the diagnosis of cryptosporidiosis in AIDS and immunocompetent patients. Eur $J$ ClinMicrobiol Infect Dis, 14, 46-49.

[57] CMO's Update 23, 1999. Cryptosporidium in water: clarification of the advice to

[58] to the immunocompromised Department of Health, London,p.4 available

a. from

$:<$ http://www.dh.gov.uk/en/Publicationsandstatistics/Lettersandcircula rs/CMOupdate>/DH_4003594>.

[59] Cohen, S. A. (2005). Use of nitazoxanide as a new therapeutic option for persistent diarrhea: a pediatric perspective. Curr Med Res Opin 21, 999-1004.

[60] Colford, J. M., Tager, I. B., Hirozawa, A. M., Lemp, G. F., Aragon, T., \& Petersen, C. (1996). Cryptosporidiosis among patients infected with human immunodeficiency virus. Factors related to symptomatic infection and survival. Am J Epidemiol, 144, 807-816.

[61] Combee, C. L., Collinge, M. L., \& Britt, E. M. (1986) Cryptosporidiosis in a hospital-associated day-care center. Pediatr Infect Dis J, 5, 528-532.

[62] Corbett-Feeney, G. (1987). Cryptosporidium among children with acute diarrhea in the west of Ireland. $J$ Infect, 14, 79-84.

[63] Cordell, R. L., \&Addiss, D. G. (1994). Cryptosporidiosis in child care settings: a review of the literature and recommendations for prevention and control. Pediatr Infect Dis J, 13, 310-317.

[64] Current, W. L., Reese, N. C., Ernst, J. V., Bailey, W. S., Heyman, M B., \&Weistein, W. M. (1983). Human cryptosporidiosis in immunocompetent and immunodefiency persons. Study of an outbreak and experimental transmission. $N$ Engl J Med, 308, 1252-1257.

[65] Current, W. L (1984). Cryptosporidium and cryptosporidiosis. New York: Alan R Liss

[66] Current, W. L (1986). Cryptosporidium: its biology and potential for environmental transmission. Criti Rev Environ Control, 17, 21-51.

[67] Current, W. L., \& Garcia, L. S. (1991). Cryptosporidiosis ClinMicrobiol Rev, 4, 325-358.

[68] Dagan, R., Fraser, D., El-On, J., Kassis, I., Deckelbaum, R., \& Turner, S. (1995). Evaluation of an enzyme immunoassay for the detection of Cryptosporidium spp. In stool specimens from infants and young children in field studies. Am J Trop Med Hyg, 52, 134-138. [69]

[70] D'Antonio, R. G., Winn, R. E., \& Taylor, J. P. (1985). A water borne out brake of cryptosporidiosis in normal hosts. Ann Intern Med, 103 , 886-888

[71] Davis, J. J., Heyman, M. B., \& Ferrell, L. (1987). Sclerosing cholangitis associated with chronic cryptosporidiosis in a child with a congenital immunodeficiency disorder. Am J Gastroenterol, 82, 1196-2002.

[72] Delf'in, M., Sanjurjo, E., Findlay, C. M., \&Gordeeva, L. M. (1989), Cryptosporidium sp. In children with diarrhea in Cuba. Med Parazitol, 4, 36-39.

[73] Dillingham, R. A, Lima, A. A., \& Richard, L. (2002). Guerrant Cryptosporidiosis: epidemiology and impact. Microbes and Infection 1059-1066.

[74] Doumbo, O., Rossignol, J. F., Pichard, E., Traore, H. A., Dembele, T. M., Diakite, M., et al. (1997). Nitazoxanide in the treatment of cryptosporidial diarrhea and other intestinal parasitic infections associated with acquired immunodeficiency syndrome in tropical Africa. J Trop Med Hyg, 56, 637-639.

[75] Duke, L. A., Breathnach, A. S., Jenkins, D. R., Harkis, B. A., \&Codd, A. W. (1996). A mixed outbreak of Cryptosporidium and Campylobacter infection associated with a private water supply. Epidemiol Infect, 116, 303-308.

[76] El-Mahallawy, H. A., El-Din, N. H., \& Salah, F. (2004). Epidemiologic profile of symptomatic gastroenteritis in pediatric oncology patients receiving chemotherapy. Pediatr Blood Cancer, 42(4), 338-342

[77] Emmerson, A. M. (2001). Emerging waterborne infections in health-care settings. Emerg Infect Dis 7(2), 272-276.

[78] Enriquez, C., Nwachuku, N., \&Gerba, C. P. (2001). Direct exposure to animal enteric pathogens. . Rev Environ Health 16, 117-131.

[79] Enriquez, J. F., Avial, C. R., Santos, I. J., Tanaka, K. J., Vallejo, O., \& Sterling, C. R. (1997). Cryptosporidium infections in Mexican children: clinical, nutritional, enteropathogenic and diagnostic evaluations. Am J Trop Med Hyg, 56, 254-257.

[80] Essid, R., Mousli, M., Aoun, K., Rim, A., Mellouli, F., Fakher, K., et al. (2008). Identification of Cryptosporidium species infecting Human in Tunisia. Am J Trop Med Hgy, 79(5), 702-705. 
[81] Fayer, R., L, Gasbarre, P., Pasquali, A., Canals, S., Almeria, \&Zarlenga, D. (1998 a). Cryptosporidium parvum infection in bovine neonates: dynamic clinical, parasitic and immunologic patterns. Int $J$ Parasitol, 28, 49-56.

[82] Fayer, R., Morgan, U., \& Upton, S. J. (2000). Epidemiology of Cryptosporidium: transmission, detection and identification. Int $J$ Parasitol, 30, 1305-1322.

[83] Flanigan, T., Whalen, C., Turner, J., Soave, R., Toerner, J., Havlir, D., et al. (1992). Cryptosporidium infection and CD4 ${ }^{+}$counts. Annals of interalMedicien 116, 840-842.

[84] Foot, A. B., Oakhill, A., \& Mott, M. G. (1990). Cryptosporidiosis and acute leukemia. Arch Dis Child 65, 236-237.

[85] Freifeld, A. G., Walsh, T. J., \&Pizzo, P. A. (1997). Infection in the Cancer Patient (5th ed.). New York: Lippincott-Raven.

[86] Fretz, R. P., Svoboda, U. M., Ryan, Thompson, R. C., Tanners, M., \& Baumgartner, A. (2003). Genotyping of Cryptosporidium spp. isolated from human stool samples in Switzerland. Epidemiol Infect, 131, 663-667.

[87] Garcia, L. S., Archie, C., Shum, A., David, A., \& Bruckner, D. A (1992). Evaluation of a New Monoclonal antibody combination reagent for fluorescence detection of Giardia cysts and Cryptosporidiumoocysts in human fecal specimens. J ClinMicrobiol, 30(12), 3255-3257.

[88] Garcia, L. S., Bruckner, D. A., Brewer, T. C., \& Shimizu, R. Y. (1983) Techniques for the recovery and identification of Cryptosporidiumoocysts from stool specimens. J ClinMicrobiol, 18, 185-190.

[89] Garcia, L. S., \& Current, W. L. (1989). Cryptosporidiosis: clinical features and diagnosis. Clin Rev Clin Lab Sci, 27, 439-460.

[90] Garcia, L. S., \& Shimizu, R. Y. (1997). Evaluation of nine immunoassay kits (enzyme immunoassay and direct fluorescence) for detection of Giardia lamblia and Cryptosporidium parvum in human fecal specimens. J ClinMicrobiol, 35, 1526-1529.

[91] Garcia, L. S., \& Shimizu, R. Y. (2000). Detection of GardiaLambliaand Cryptosporidium parvumantigens in human fecal specimens using the Color PAC Combination rapid solid phase qualitative Immunochromatographic assay. J ClinMicrobiol, 38 , $1267-1280$

[92] Garcia, L. S., Shimizu, R. Y., Novak, S., Carroll, M., \& Chan, F. (2003). Commercial assay for detection of Giardia lamblia and Cryptosporidium parvum antigens in human fecal specimens by rapid solid-phase qualitative immunochromatography. J ClinMicrobiol, 41, 209-212.

[93] Gelletli, R., Stuart, J., Soltano, N., Armstrong, R., \& Nichols, G (1997). Cryptosporidiosis associated with school milk. Lancet, 350, $1005-1006$

[94] Gentile, G., Caprioli, A., Donelli, G., Venditti, M., Mandelli, F., \& Martino, P. (1990). Asymptomatic carriage of Cryptosporidium in two patients with leukemia. Am J Infect Control 18, 127-128.

[95] Gentile, G., Venditti, M., Micozzi, A., Caprioli, A., Donelli, G., Tirindelli, C., et al. (1991). Cryptosporidiosis in patients with hematological malignancies. Rev Infect Dis, 13, 842-846.

[96] Glaberman, S., Moore, J. E., \& Lowery, C. J. (2002). Three drinking water- associated cryptosporidiosis outbreaks, Northern Ireland. Emerg Infect Dis, 8, 631-633.

[97] Glaser, C. A., Safrin, S., A. Reingold, A., \& Newman, T. B. (1998) Association between Cryptosporidium infection and animal exposure in HIV-infected individuals. $J$ Acquir Immune DeficSyndrHum Retrovirol, 17, 79-82

[98] Goh, S., Reacher, M., \&Casemore, D. P. (2004). Sporadic cryptosporidiosis, North Cumbria, England, 1996-2000. Emerg Infect Dis 10, 1007-1015.
[99] Griffin, K., Mattahi, E., Hommel, M., Weitz, J. C., Baxby, D., \& Hart C. A. (1992). Antigenic diversity among oocysts of clinical isolates of Cryptosporidium parvum. J Protozool Res, 2, 97-101.

[100] Griffiths, J. I. C. (1998). Human cryptosporidiosis: Epidemiology, transmission, clinical disease, treatment, and diagnosis.AdvParasitol $40,37-85$.

[101] Harp, J. A. (2003). Cryptosporidium and host resistance: historical perspective and some novel approaches. Animal Health Research Reviews 4(1), 53-62.

[102] Havelaar, A. H., De Hollander, A. E., Teunis, P. F., Evers, E. G., Van Kranen, H. J., \&Versteegh, J. F. (2000). Balancing the risks and benefits of drinking water desinfection: disability adjusted life-years on the scale. Environ Health Perspect 108, 315-321.

[103] Hayes, E. B., Matte, T. D., O'Brien, T. R., McKinley, T. W., Logsdon, G. S., Fose, J. B., et al. (1989). Large community outbreak of cryptosporidiosis due to contamination of a filtered public water supply. N Engl J Med, 320, 1372-1376.

[104] Heine, J., Moon, H. W., \&Woodmansee, D. B. (1984). Persistent Cryptosporidium infection in congenitally athymic (nude) mice. Infect Immun 43, 856-859.

[105] Henrikson, S. A., \&Pholenz, J. F. L. (1981). Staining of cryptosporidia by a modified Ziehl -Neelsen technique. Acta Vet Scand, 22, 594-596.

[106] Hershberg, R. M., \& Mayer, L. F. (2000). Antigen processing and presentation by intestinal epithelial cells-polarity and complexity. Immunology Today 21, 123-128.

[107] Hewitt, R. G., Yiannoutsos, C. T., Higgs, E. S., Carey, J. T., Geiseler, P. J., Soave , R., et al. (2000). Paramomycin: no more effective than placebo for tratment of cryptosporidiosis in patients with advanced human immunodeficiency virus infection. Clin Infect Dis, 31 1084-1092.

[108] Higgins, J. A., Fayer, R., Trout, J. M., Xiao, L., Lal, A. A., Kerby, S., et al. (2001). Real-time PCR for the detection of Cryptosporidium parvum. J Microbiol Methods, 47, 323-337.

[109] Hijjawi, N. S., Meloni, B. P., Ryan, U. M., Olson, M. E., \& Thompson, R. C. (2002). Successful in vitro cultivation of Cryptosporidium andersoni: evidence for the existence of novel extracellular stages in the life cycle and implications for the classification of Cryptosporidium. Int J Parasitol 32, 1719-1726.

[110] Hoepelman, A. I. (1996). Current therapeutic approaches to cryptosporidiosis in immunocompromised patients. $J$ AntimicrobChemother 37, 872-880.

[111] Holley, H. P., \& Thiers, B. H. (1986). Cryptosporidiosis in a patient receiving immunosuppressive therapy: possible activation of laten infection. Dig Dis Sci 31, 1004-1007.

[112] Horman, A., Korpela, H., Sutinen, J., Wedel, H., \&Hanninen, M. L. (2004). Meta-analysis in assessment of the prevalence and annual incidence of Giardia spp. and Cryptosporidium spp. infections in humans in the Nordic countries. Int J Parasitol, 34, 1337-1346.

[113] Hughes, W. T., Armstrong, D., Bodey, G. P., Brown, A. E., E, E. J., \& Feld, R. (1997). Guidelines for the use of antimicrobial agents in neutropenic patients with unexplained fever. Clin Infect Dis, 25 , $551-573$

[114] Hunt, E., Q. Fu, Armstrong, M. U., Ren-nix, D. K., Webster, D. W. Galanko, J. A., Chen, W., et al. (2002). Oral bovine serum con-centrate improves cryptosporidial enteritis in calves. Pediatric Research, 51, 370-376

[115] Hunter, P. R., Hughes, S., \& Woodhouse, S. (2004 b). Sporadic cryptosporidiosis case-control study with genotyping. Emerg Infect Dis, 10, 1241-1249. 
[116] Hunter, P. R., \& Nichols, G. (2002). Epidemiology and clinical feature of Cryptosporidium infection in immunocompromised patients. ClinMicrobiol Rev, 15, 145-154.

[117] Isaacs, D., Hunt, G. A., Phillips, A. D., Price, E. H., Raafat, F., \& Walker-Smith, J. A. (1985). Cryptosporidiosis in immunocompetent children. J ClinPathol, 38, 76-81.

[118] Jędrzejewski, S. z., \&Majewska, A. C. (2007). Contamination of fresh food products with dispersive stages of intestinal parasites. WiadParazytol 53, 104.

[119] Jex a, A. R., Smith b, H. V., Monis c, P. T., Campbell a, B. E., \& Gasser, R. B. (2008). Cryptosporidium-Biotechnological advances in the detection, diagnosis and analysis of genetic variation. BiotAdva, 26, 304-317.

[120] Johnston, S. P., Ballard, M. M., Beach, M. J., Causer, L., \& Wilkins, P. P. (2003). Evaluation of three commercial assays for detection of Giardia and Cryptosporidium organisms in fecal specimens. $J$ ClinMicrobiol, 41, 623-626.

[121] Karanis, P., Kourenti, C., \& Smith, H. (2007). Waterborne transmission of protozoan parasites: a worldwide review of outbreaks and lessons learnt. J Water and Health, 5, 1-38.

[122] Katanik, M. T., Schneider, S. K., Rosenblatt, J. E., Hall, G. S., \&Procop, G. W. (2001). Evaluation of ColorPACGiardia/Cryptosporidium rapid assay and ProSpecTGiardial Cryptosporidiummicroplate assay for detection of Giardia and Cryptosporidium in fecal specimens. J ClinMicrobiol, 39, 4523-4525.

[123] Katsumata, T., Hosea, D., Wasito, E. B., Kohno, S., Hara, K., Soeparto, P., et al. (1998). Cryptosporidiosis in Indonesia: a hospitalbased study and a community-based survey. American J Trop Med Hyg 59, 628-632

[124] Katz, M. D., Erstad, B. L., \& Rose, C. (1988). Treatment of severe Cryptosporidium-related diarrhea with octreotide in a patient with AIDS. Drug IntellClin Pharm, 22, 134-136.

[125] Kavanagh, A. M., Goller, J. L., King, T., Jolley, D., Crawford, D., \&Turrell , G. (2005). Urban area disadvantage and physical activity: a multilevel study in Melbourne, Australia. J EpidemiolCommun Health, 59(11), 934-940.

[126] Kern, W., Mayer, S., Kreuzer, P., \&Vanek, E. (1987). Low prevalence of intestinal cryptosporidiosis among immunocompetent and immunocompromised patients with and without diarrhea in southern Germany. Infection, 440-443.

[127] Khalil , H. M., Makled, M. K., Azab, M. E., Abdalla, H. M., Sherif, E. A., \&Nassef, N. S. (1991). Opportunistic parasitic infections in immunocompromised hosts. J Egypt SocParasitol, 21, 657-658.

[128] Kim, L. S., Hadley, W. K., \&Stansell, J. (1998). Declining prevalence of cryptosporidiosis in San Francisco. Clin Infect Dis 27, 655-656.

[129] Kirkpatrick, B. D., Daniels, M. M., Jean, S. S., Pape, J. W., Karp, C., Littenberg, B., et al. (2002). Cryptosporidiosis stimulates an inflammatory intestinal response in malnourished Haitian children. $J$ Infect Dis, 186, 94-101.

[130] Kirkpatrick, B. D., Haque, R., Duggal, P., Mondal, D., Larsson, C., Peterson, K., et al. (2008). Association between Cryptosporidium infection and human leukocyte antigen class I and class II alleles. $J$ Infect Dis, 197(3), 474-478.

[131] Koch, K., Phillips, D., \&Aber, R. (1985). Cryptosporidiosis in hospital personnel: evidence for person-to-person transmission. Ann Intern Med, 158, 647-648.

[132] Kuhls, T. L. (2000). Cryptosporidiosis during childhood. SeminPediatr Infect Dis, 11, 213-219.

[133] Lacroix, C., Berthier, M., Agius, G., Bonneau, D., Pallu, B., \&Jacquemin, J. L. (1987). Cryptosporidiumoocysts in immunocompetent children: Epidemiologic investigations in the day-care centers of Poitiers, France. Eur J Epidemiol, 3, 381-385.
[134] Lai, K. F. P. (1992). Intestinal protozoan infections in Malaysia. Southeast Asian J Trop Med Public Health, 23, 578-586.

[135] Langer, R. C., \& Riggs, M. W. (1999). Cryptosporidium parvum apical complex glycoprotein CSL contains a sporozoite ligand for intestinal epithelial cells, Infect. Infect Immun, 67, 5282-5291.

[136] Laurent, F., Kagnoff, M. F., Savidge, T. C., Naciri, M., \&Eckmann, L. (1998). Human intestinal epithelial cells respond to Cryptosporidium parvum infection with increased prostaglandin $\mathrm{H}$ synthase 2 expressions and prostaglandin E2 and F2a production. Infect Immun, 66(4), 1787-1790.

[137] LeChevallier, M. W., Norton, W. D., \& Lee, R. G. (1991). Giardia and Cryptosporidium spp. in filtered drinking water supplies. Appl Environ Microbiol, 57, 2617-2621.

[138] Levine, N. D. (1985). Phylum II Apicomplexa: Allen Press, Lawrence.

[139] Lewis, I. J., Hart, C. A., \&Baxby, D. (1985). Diarrhea due to cryptosporidium in acute lymphoblastic leukemia. Arch Dis Child 60 , $60-62$.

[140] Ludin, C. M., Afifi, S. A., Hasenan, N., Maimunah, A., \&Anuar, A. K (1991). Cryptosporidiosis among children with acute gastroenteritis in the pediatric ward in the General Hospital, Penang. Asian J Trop Med Public Health, 22, 200-205.

[141] Ma, P., \& Soave, R. (1983). The stool examination for cryptosporidiosis in 10 homosexual men protracted watery diarrhea. $J$ Infect Dis, 147, 824-828.

[142] Mackenzie, W. R., Schell, W. L., \& Blair, K. A. (1995). Massive outbreak of waterborne Cryptosporidium infection in Milwaukee, Wisconsin: recurrence of illness and risk of secondary transmission. Clin Infect Dis, 21, 56-62.

[143] MacPherson, D. W., \& McQueen, R. (1993). Multiattribute Evaluation of six diagnostic methods. J ClinMicrobiol, 31(2), 198-202.

[144] Madore, M. S., Rose, J. B., Gerba, C. P., Arrowood, M. J., \& Sterling, C. R. (1987). Occurrence of Cryptosporidiumoocysts in sewage effluents and selected surface waters. J. Parasitol, 73, 702-705.

[145] Maggi, P., Larocca, A. M. V., Quarto, M., Serio, G., Brandonisio, O., Angarano, G., et al. (2000). Effect of Antiretroviral Therapy on Cryptosporidiosis and Microsporidiosis in Patients Infected with Human Immunodeficiency Virus Type 1. Eur J ClinMicrobiol Infect Dis 19, 213-217.

[146] Mahadi, N. K., Maysloon, A. A., \&Genan, K. H. (2007) Cryptosporidiosis and immunological status in children with malignancies. Med J Bash Univ, 25, 1-6.

[147] Manabe, Y. C., Clark, D. P., Moore, R. D., Lumadue, J. A., Dahlman, H. R., Belitsos, P. C., et al. (1998). Cryptosporidiosis in patients with AIDS: correlates of disease and survival. Clin Infect Dis, 536-542.

[148] Marshall, M. M., Naumovitz, D., Ortega, Y., \& Sterling, C. R. (1997). Waterborne protozoan pathogens. ClinMicrobiol Rev 10, 67-85.

[149] Martino, P., Gentile, G., \&Caprioli, A. (1988). Hospital-acquired cryptosporidiosis in a bone marrow transplant unit. J Infect Dis 158 , $647-648$

[150] Mata, L., Bolanos, H., Pizarro, D., \&Vives, M. (1984) Cryptosporidiosis in children from some highland Costa Rican rural and urban areas. Am J Trop Med Hyg, 33, 24-29.

[151] Matsubayashi, M., Abe, N., \&Takami, K. (2004). First record of Cryptosporidium infection in a raccoon dog, (Nyctereutesprocyonoidesviverrinus). Vet Parasitol 120, 171-175.

[152] McCole, D. F., Eckmann, L., Laurent, F., \&Kagnoff, M. F. (2000). Intestinal Epithelial cells Apoptosis following Cryptosporidium parvum infection. Infection and Immunity, 68, 1710-1713. 
[153] McDonald, V., \& Bancroft, G. J. (1994). Mechanisms of innate and acquired resistance to Cryptosporidium parvum infection in SCID mice. Parasite Immunol, 16, 315-320.

[154] McLauchlin, J., Amar, C. F. L., Pedraza-Diaz, S., Mieli-Vergani, G., Hdzic, N., \& Davies, E. G. (2003). Polymerase chain reaction-based diagnosis of infection with Cryptosporidium in children with primary immunodeficiencies. The PediatrInfec Dis J, 22, 329-334.

[155] McLauchlin, J., Pedraza-Diaz, S., Amar-Hoetzeneder, C., \& Nichols, G. L. (1999). Genetic characterization of Cryptosporidium strains from 218 patients with diarrhea diagnosed as having sporadic cryptosporidiosis. J ClinMicrobiol, 37(10), 3153-3158.

[156] McNabb, S. J. N., Hensel, D. M., Welch, D. F., Heibel, H., McKee, G. L., \&Instre, G. G. (1985). Comparison of sedimentation and flotation techniques for identification of Cryptosporidium sp. oocysts in a large outbreak of human diarrhea. J ClinMicrobiol, 22, 587-589.

[157] Mead, G. M., Sweetenham, J. W., \&Ewins, D. L. (1986). Intestinal cryptosporidiosis: a complication of cancer treatment. Cancer Treat Rep, 70, 769-770.

[158] Mead, J. (2002). Cryptosporidiosis and the challenges of chemotherapy. Drug Resist Update, 5, 47-57.

[159] Medzhitov, R. (2001). Toll-like receptors and innate immunity. Nat Rev Immunol, 1(2), 135-145.

[160] Meisel, J. L., Perera, D. R., Meligro, C., \& Rubin, C. E. (1976). Overwhelming watery diarrhea associated with Cryptosporidium in an immunosuppressed patient. Gastroenterology, 70, 1156-1160.

[161] Menon, B. S., Abdullah, M. S., Mahamud, F., \& Singh, B. (1999). Intestinal parasites in Malaysian children with cancer. J Trop. Pediatr, $45,241-242$.

[162] Menon, B. S., Abdullah, S., Mahamud, F., Morgan, U. M., Malik, A S., Choo, K. E., et al. (2001). Low prevalence of Cryptosporidium parvum in hospitalized children in Kota Bharu, Malaysia. Southeast Asian J Trop Med Public Health, 32(2), 319-322.

[163] Merlani, G. M., \&Francioli, P. (2003). Established and emerging waterborne nosocomial infections. CurrOpin Infect Dis 16(4), 343-347.

[164] Miao, Y. M., Awad-El-Kariem, F. M., Franzen, C., Ellis, D. S., Muller, A., Counihan, H. M., et al. (2000). Eradication of cryptosporidia and microsporidia following successful antiretroviral therapy. J Acquir Immune DeficSyndr, 25, 124-129.

[165] Miller, R. A., Holmberg, R. E., \& Clausen, C. R. (1983). Life-threatening diarrhea caused by Cryptosporidium in a child undergoing therapy for acute lymphocytic leukemia. J Pediatr 103, 256-259.

[166] Miller, W. A., Gardner, I. A., Atwill, E. R., Leutenegger, C. M., Miller, M. A., Hedrick, R. P., et al. (2006). Evaluation of methods for improved detection of Cryptosporidium spp. in mussels (Mytiluscalifornianus). J Microbiol Methods 65, 367-379.

[167] Molbak, K., Aaby, P., Hojlyng, N., \& da Silva, A. P. (1994). Risk factors for Cryptosporidium diarrhea in early childhood: a case-contro study from Guinea-Bissau, West Africa. Am J Epidemiol 139, 734-740.

[168] Moodley, D., Jackson, T., Gathiram, V., \& Van den Ende, J. (1991). Cryptosporidium infectious in children in Durban: seasonal variation, age distribution and disease status. South Afr Med J, 79, 295-297.

[169] Moore, A. G., Vesey, G., Champion, A., Scandizzo, P., Deere, D., Veal, D., et al. (1998). Viable Cryptosporidium parvumoocysts exposed to chlorine or other oxidizing conditions may lack identifying epitopes. Int J Parasitol, 28, 1205-1212.

[170] Morgan, U. M., Constance, C. C., Forbes, D. A., \& Thompson, R. C. (1998). Differentiation between $C$. parvum using rDNA sequencing and direct PCR analysis. J. Parasitol, 36, 995-998.

[171] Morgan, U. M., Pallant, L., Dwyer, B. W., Forbes, D. A., Rich, G., \& Thompson, R. C. A. (1998). Comparison of PCR and microscopy for detection of Cryptosporidium parvum in human faecal specimens: clinical trial. J ClinMicrobiol, 36(4), 995-998.

[172] Morgan, U. M., Sturdee, A. P., \& Singleton, G. (1999b). The Cryptosporidium 'mouse' genotype is conserved across geographic areas. J ClinMicrobiol 37, 1302-1305.

[173] Morgan, U., Weber, R., Xiao, L., Sulaiman, I., Thompson, R. C. Ndiritu, W., et al. (2000a). Molecular characterization of Cryptosporidium isolates obtained from human immunodeficiency virus-infected individuals living in Switzerland, Kenya, and the United States. J ClinMicrobiol, 38, 1180-1183.

[174] Morgan-Ryan, U. M., Fall, A., Ward, L. A., Hijjawi, N., Sulaiman, I., Fayer, R., et al. (2002). Cryptosporidium hominissp (Apicomplexa: Cryptosporidiidae) from Homo sapiens. J EukaryotMicrobiol, 49 , 433-444

[175] Navin, T. R., \&Juranek, D. D. (1984). Cryptosporidiosis: clinical, epidemiologic, and parasitologic review. Rev Infect Dis, 6, 313-327.

[176] Navin, T. R. (1985). Cryptosporidiosis in humans: review of recent epidemiologic studies. Eur J Epidemiol, 1, 77-83.

[177] Navin, T. R., \& Hardy, A. M. (1987). Cryptosporidiosis in patients with AIDS. J Infect Dis 155, 150-154.

[178] Neill, M. A., Rice, S. K., Ahmad, N. V., \&Flanigan, T. P. (1996) Cryptosporidiosis: an unrecognized cause of diarrhea in elderly hospitalized patients. Clin Infect Dis, 22, 168-170.

[179] Nelson, W. E., Behrman, R. E., \&Kliegman, R. M. (1996). Nelson's Textbook of Pediatrics. London: WB Saunders Co: Philadelphia.

[180] Nesterenko, M. V., Woods, K. M., \& Upton, S. J. (1999) Receptor/ligand interactions between Cryptosporidium parvum and the surface of the host cell. BiochimBiophysActa 1454, 165-173.

[181] Newman, R. D., Jaeger, K. L., Wuhib, T., Lima, A. A., Guerrant, R. L., \& Sears, C. L. (1993). Evaluation of an antigen capture enzyme-linked immunosorbent assay for detection of Cryptosporidiumoocysts. J ClinMicrobiol 31, 2080-2084.

[182] Newman, R. D., Sears, C. L., Moore, S. R., Nataro, J. P., Wuhib, T., Agnew, D. A., et al. (1999). Longitudinal study of Cryptosporidium infection in children in northeastern Brazil. J Infect Di, 180, 167-175.

[183] Nime, F. A., Burek, J. D., Page, D. L., Holscher, M. A., \& Yardley, J. H. (1976). Acute enterocolitis in a human being infected with the protozoan Cryptosporidium. Gastroenterology, 70, 592-598.

[184] Nimri, L. F., \&Hijazi, S. S. (1994). Cryptosporidium. A cause of gastroenteritis in preschool children in Jordan. J ClinGestroenterol, 19 (4), 288-291

[185] O’Donoghue, P. J. (1995). Cryptosporidium and cryptosporidiosis in man and animals. Intern J Parasito, 25, 139-195.

[186] Okhuysen, P. C., Chappell, C. L., Crabb, J., Valdez, L. M., Douglass, E. T., \& Du-Pont, H. L. (1998). Prophylactic effect of bovine anti-Cryptosporidiumhyperimmunecolos-trum immunoglobulin in healthy volunteers challenged with C. parvum. ClinInf Dis, 26, 1324-1329.

[187] Okhuysen, P. C., Chappell, C. L., Crabb, J. H., Sterling, C. R., \& Du-Pont , H. L. (1999). Virulence of three distinct Cryptosporidium parvumisolates for healthy adults. J Infect Dis, 180, 1275-1281.

[188] Oshiro, E. T., Dorvol, M. E., Nunes, V. L., Silva, M. A., \& Said, L. A (2000). Prevalence of Cryptosporidium parvum among children of less than 5 years of age in the urban zone of Campo Grande, Mato Grosso do Sul State, Brazil, 1996. Rev Soc Bras Med Trop, 33, 277-280.

[189] Pal, S., Bhattacharya, S. K., Das, P., Chaudhuri, P., \& Dutta, P. (1989). Occurrence and significance of Cryptosporidium infection in Calcutta. Trans $R$ Soc Trop Med Hyg, 83, 520-521.

[190] Payne, P., Lancaster, L. A., Heinzman, M., \&Cutchan, J. A. M.(1984). Identification of Cryptosporidium in patients with acquired immunodeficiency syndrome. $N$ Engl J Med., 309, 613-614. 
[191] Peng, M. M., Xiao, L., \& Freeman, A. R. (1997). Genetic polymorphism among Cryptosporidium parvum isolates: evidence of two distinct human transmission cycles. Emerg Infect Dis 3, 567-573.

[192] Perch, M., Sodemann, M., Jakobsen, M. S., Valentiner-Branth, P., Steinsland, H., Fischer, T. K., et al. (2001). Seven years' experience with Cryptosporidium parvum in Guinea-Bissau, West Africa. Ann Trop Paediatr, 21, 313-318.

[193] Petersen , C., Gut, J., Doyle, P. S., Crabb, J. H., Nelson, R. G., \& Leech, J. H. (1992). Characterization ofa $>900,000-\mathrm{Mr}$ Cryptosporidiumparvumsporozoite glycoprotein recognized by protective hyperimmune bovine colostral immunoglobulin. Infect Immun 60(12), 5132-5138.

[194] Pettoello-Mantovani, M., Di Martino, L., \&Dettori, G. (1995). A symptomatic carriage of intestinal Cryptosporidium in immunocompetent and immunodeficient children: a prospective study. Pediatr Infect Dis J, 14(12), 1042-1047.

[195] Pieniazek, N. J., Bornay-Llineares, F. J., Slemenda, S. B., da Silva, A J., Moura, I. N. S., Arrowood, M. J., et al. (1999). New Cryptosporidium genotypes in HIV-infected persons. EmergInf Dis, 5 , 444-449.

[196] Pitlik, S. O., Fainstein, V., Garza, Guarda, L., Bolivar, R., Rios, A., et al. (1983). Human cryptosporidiosis: spectrum of disease. Report of six cases and review of the literature. Arch Intern Med 143, 2269-2275.

[197] Priest, J. W., Bern, C., Roberts, J. M., Kwon, J. P., Lescano, A. G., \&Checkley, W. (2005). Changes in serum immunoglobulin G levels as a marker for Cryptosporidium sp. infection in Peruvian children. $J$ ClinMicrobiol, 43, 5298-5300.

[198] Puech, M. C., McAnulty, J. M., Lesjak, M., Shaw, N., Heron, L., \& Watson, J. M. (2001). A statewide outbreak of cryptosporidiosis in New South Wales associated with swimming at public pools. Epidemiol Infect, 12, 389-396.

[199] Quilez, J., Sanchez-Acedo, C., Clavel, A., delCacho, E., \& Lopez-Bernad, F. (1996). Comparison of an acid-fast stain and a monoclonal antibody-based immunofluorescence reagent for the detection of Cryptosporidiumoocysts in faecal specimens from cattle and pigs. Vet Parasitol, 67, 75-81.

[200] Quiroz, E. S., Bern, C., MacArthur, J. R., \& Xiao, L. (2000). An outbreak of cryptosporidiosis linked to a food handler. J Infect Dis 181 , 695-701.

[201] Ramirez, N. E., Ward, L. A., \&Sreevatsan, S. (2004). A review of the biology and epidemiology of cryptosporidiosis in humans and animals. Microbes and Infection, 6, 773-785.

[202] Ravn, P., Lundgren, J. D., Kjaeldgaard, P., Holten-Anderson, W., Hojlyng, N., \& Nielsen, J. O. (1991). Nosocomial outbreak of cryptosporidiosis in AIDS patients. BMJ, 302, 277-280.

[203] Regnath, T., Klemm, T., \& Ignatius, R. (2006). Rapid and accurate detection of GardiaLamblia and Cryptosporidium spp. antigens in human fecal specimens by new commercially available qualitative immunochromatographic assays. J ClinMicrobiol Infect Dis, 25, 807-809.

[204] Riggs, M. W., Stone, A. L., Yount, P. A., Langer, R. C., Arrowood , M J., \& Bentley, D. L. (1997). Protective monoclonal antibody defines a circum-sporozoite-like glycoprotein exoantigen of Cryptosporidium parvumsporozoites and merozoites. J Immunol 158, 1787-1795.

[205] Robert, B., Ginter, A., Antoine, H., Collard, A., \&Coppe, P. (1990). Diagnosis of bovine cryptosporidiosis by an enzyme-linked immunosorbent assay. Vet Parasitol 37, 1-8.

[206] Roberts, W. G., Green, P. H. R., Ma, J., Carr, M., \& Ginsberg, A. M (1989). Prevalence of cryptosporidiosis in patients undergoing endoscopy: evidence for an asymptomatic carrier state. Am J Med, 87, 537-539.

[207] Robertson, B., Sinclair, M. I., \& Forbes, A. B. (2002). Case-control studies of sporadic cryptosporidiosis in Melbourne and Adelaide, Australia. Epidemiol Infect 128, 419-431.
[208] Robinson, R. A., \& Pugh, R. N. (2002). Dogs, zoonoses and immunosuppression. $J R$ Soc Health 122, 95-98.

[209] Rosenblatt, J. E., \& Sloan, L. M. (1993). Evaluation of an enzyme-linked immunosorbent assay for detection of Cryptosporidium spp. in stool specimens. J ClinMicrobiol, 31, 1468-1471.

[210] Rossignol, J. F., Hidalgo, H., Feregrino, M., Higuera, F., Gomez, W. H., Romero, J. L., et al. (1998). A double-'blind' placebo-controlled study of nitazoxanide in the treatment of cryptosporidialdiarrhoea in AIDS patients in Mexico. Trans RoySoc Trop Med Hyg, 92, 663-666.

[211] Rossignol, J. F., Ayoub, A., \& Ayers, M. S. (2001). Treatment of diarrhea caused by Cryptosporidium parvum: A prospective randomized, double-blind, placebo-controlled study of Nitazoxanide. $J$ Infect Dis, 184, 103-106.

[212] Roy, S. L., DeLong, S. M., \&Stenzel, S. A. (2004). Risk factors for sporadic cryptosporidiosis among immunocompetent persons in the United States from 1999 to 2001. J ClinMicrobiol $\square \square, 2944-2951$.

[213] Rudrapantna, J. S., Kumar, V., \& Sridhar, H. (1997). Intestinal parasitic infections in patients with malignant diseases. $J$ Diarrhoea Dis Res, 15(2), 71-74.

[214] Salon, S., Showwa, R. E., Masri, M. E., Khalil, M., Blundell, N., \& Hart, C. A. (1990). Cryptosporidiosis in children in Gaza. Ann Trop Pediatr, 11, 277-281

[215] Schuster, W., Fischer , R., Alsleben, S., \& B, S. (1991). Cryptosporidium spp. in stool specimens from diarrhoeic and asymptomatic individuals in the Magdeburg area (East Germany). AngewParasitol 12, 187-190. 